University of Nebraska - Lincoln

DigitalCommons@University of Nebraska - Lincoln

Papers in Natural Resources

Natural Resources, School of

September 1995

Nectarivorous feeding mechanisms in bats

Patricia W. Freeman

University of Nebraska-Lincoln, pfreeman1@unl.edu

Follow this and additional works at: https://digitalcommons.unl.edu/natrespapers

Part of the Natural Resources and Conservation Commons

Freeman, Patricia W., "Nectarivorous feeding mechanisms in bats" (1995). Papers in Natural Resources.

16.

https://digitalcommons.unl.edu/natrespapers/16

This Article is brought to you for free and open access by the Natural Resources, School of at DigitalCommons@University of Nebraska - Lincoln. It has been accepted for inclusion in Papers in Natural Resources by an authorized administrator of DigitalCommons@University of Nebraska - Lincoln. 
Published in Biological Journal of the Linnean Society 56 (1995), pp. 439-463. Copyright (C) 1995 The Linnean Society of London. Published by Blackwell Publishing. Used by permission. "The definitive version is available at http://blackwell-synergy.com."

\title{
Nectarivorous feeding mechanisms in bats
}

\author{
Patricia W. Freeman \\ Division of Zoology, University of Nebraska State Museum \\ Lincoln, NE 68588-0574, U.S.A.
}

Submitted July 1994; accepted for publication 10 November 1994

\begin{abstract}
Cranio-dental characteristics are quantified between micro- and megachiropteran nectarivores and compared with microchiropteran animalivores, frugivores, and megachiropteran frugivores. Microchiropteran nectarivores share many characteristics with megachiropteran nectarivores and frugivores, but differ in having a long, narrow head. Megachiropterans have wide zygomata, which would allow for more jaw musculature. Diminutive cheekteeth are characteristic of nectarivory in both suborders, but both have relatively large canines. Teeth in nectarivores can occupy as little as a tenth of the palatal area compared to nearly two-thirds in microchiropteran animalivores. The proportion that the dilambdodont stylar shelf occupies of molars in microchiropteran nectarivores can be as much as that in microchiropteran animalivores (insectivorous and carnivorous bats) or as little as that in microchiropteran frugivores but not as extreme as either. In addition to diminutive teeth, nectarivores have fused mandibles and upper canines that are worn from contact with the lower canines (thegosis). These characteristics may be necessary for the lower jaw to support an elongated, mobile tongue. While microchiropteran nectarivory, frugivory, and carnivory probably evolved independently from an insectivorous microchiropteran ancestor, megachiropteran nectarivory probably evolved from megachiropteran frugivory or the reverse.
\end{abstract}

KEY WORDS: nectarivory, feeding mechanisms, cranio-dental adaptations, Chiroptera, bats, functional morphology.

\section{CONTENTS}

$\begin{array}{ll}\text { Introduction } & 439 \\ \text { Methods } & 441 \\ \text { Results } & 442 \\ \quad \text { Cranial features } & 443 \\ \quad \text { Dental areas } & 447 \\ \text { Discussion } & 450 \\ \text { Conclusions } & 459 \\ \text { Acknowledgements } & 459 \\ \text { References } & 460 \\ \text { Appendix 1. Species measured } & 462 \\ \text { Appendix 2. Measurements } & 463\end{array}$

\section{INTRODUCTION}

Microchiropteran nectar-feeding bats have been studied as a discrete phylogenetic entity and have been the subject of substantial morphological scrutiny (Winkelman, 1971; Phillips, 1971; Griffiths, 1982). Here, I examine nectarivory across Chiroptera 
and compare cranio-dental adaptations for nectarivory, frugivory, and animalivory. Nectarivorous bats have long, narrow snouts and diminutive teeth (Miller, 1907; Hill \& Smith, 1984; Vaughan, 1986). However, neither this well-known cranial feature nor the amount of area the teeth occupy on the palate have been quantified and compared with bats of different food habits. Quantifying feeding adaptations in nectarivorous bats is part of a series of studies exploring and quantifying the functional diversity in the skulls and teeth in chiropterans (Freeman, 1979, 1981, 1984, 1988, 1992). This study differs from past work in that it includes megachiropterans, bats which may or may not be phylogenetically close to microchiropterans, but bats that have similar morphological adaptations for nectar-feeding.

Slaughter (1970) explored evolutionary trends in dentitions of bats but commented that the comparative functional morphology as it relates to diet had been neglected. My studies indicate that insectivorous bats eating hard- bodied prey have thicker jaws, better developed cranial crests, fewer but larger teeth, longer canines, and more abbreviated $\mathrm{M}^{3}$ s than species eating soft-bodied prey (Freeman, 1979, 198 1). Carnivorous bats, those eating vertebrate prey, have more elongated skulls, larger brain volumes and larger pinnae, lengthened metastylar ridges on the upper molars, and larger protoconids on the lower molars compared to insectivorous bats; but there is no distinct boundary where insectivory ends and carnivory begins (Freeman, 1984). Here as earlier (Freeman, 1988) I lump insectivores and carnivores into a category of animalivores.

The most derived microchiropteran fruit-eating bats have small canines, wide palates, and close-fitting postcanine teeth with a distinctive labial rim. The labial rim of the lower teeth nests inside the labial rim of the upper teeth like opposing cookie-cutters. The upper rim is the ectoloph that has been pushed to the labial edge of the teeth. Microchiropteran frugivores have a greater allocation of tooth area at the anterior end of the toothrow, while animalivorous species have more at the posterior end. Palates of frugivores are wider than long while the opposite is true for the more strictly carnivorous species. Omnivorous bats such as Phyllostomus hastatus, Carollia perspicillata, and Sturnira lilium have a more equal allocation of area to more kinds of teeth on the tooth-row than do frugivores or animalivores (Freeman, 1988).

As in earlier studies I have been interested in how the nature of items eaten may affect dental and cranial morphology. Pollen is taken both in the process of nectar-feeding as well as independently and is considered the main source of protein of obligate nectarivores. It seems unlikely that nectar and tiny grains of pollen affect hard structures like teeth. Pollen, reportedly, is broken down chemically in bats by saliva, digestive juices, or possibly by ingested urine (Howell, 1974; Hill \& Smith, 1984). The tongue gathers nectar, which is found within shallow to deep corollas of flowers. The tongue is modified to protrude well beyond the margin of the chin and is larger because of muscles that control extension and retraction. Three things happen in nectarivores-the rostrum gets narrower and longer to fit inside deeper corollas, the tongue elongates to extend longer distances, and the teeth become smaller. Smaller teeth are probably a result of a larger tongue. As the role of the teeth diminishes, the role of the elongated jaws changes from a tooth-bearing structure to that of a tongue-supporting 
structure. The weight and activity of the tongue during feeding must be supported by the jaws. Here I quantify characteristics in teeth, jaws, and crania that may be common to nectarivorous bats; examine the diversity among nectarivores; and compare nectarivores with frugivorous and animalivorous bats.

\section{METHODS}

My sample of nectarivorous bats includes nearly all known species of nectar-feeding bats of the family Phyllostomidae, bats from the subfamily Macroglossinae, and three non-macroglossine megachiropterans. I compared these with frugivorous and animalivorous species from seven microchiropteran families (Freeman, 1984; 1988) and five more frugivorous pteropids (Appendix 1). Thirty-one linear and areal measurements or characteristics that are functionally important to feeding were taken on nearly all 80 species (Appendix 2). I took areas in occlusal view around the crowns of the teeth with the toothrow oriented as parallel to the horizontal plane as possible. Fourteen animalivores are missing certain areal quantities, which are noted in the appendices, and teeth that are naturally absent from the toothrow are treated as missing data. Descriptions and illustrations of measurements are in previous papers (Freeman, 1984, 1988). With the exception of phyllostomid frugivores, where there are ten and five specimens for each species, all other species are represented by a single male skull in perfect or near perfect condition. On occasion a perfect skull of a female was used instead of an imperfect skull of a male. As in previous studies I also measured the height of the dentary condyle relative to the level of the toothrow; however because some of these values were negative they are not included in the principal components analysis, which is done on log-transformed data.

To increase diversity among megachiropteran nectarivores, I included not only species of the nectarivorous macroglossines but also three species outside the subfamily Macroglossinae (Pteropus scapulatus, Epomops buettikoferi, and Scotonycteris zenkeri) for which $I$ did not know food habits but which specimens had elongated rostra and diminutive teeth. I considered the remaining more robust megachiropterans to be more frugivorous. The stylar shelf in the microchiropteran Brachyphylla may not be homologous to that of stenodermatine bats (Slaughter, 1970; Griffiths, 1985), but it does appear to be functionally similar (ibid: 546). Finally, one may question including both Hipposideros commersoni gigas and H. c. commersoni. The former subspecies has been listed historically as a separate species, H. gigas, because of its large size (Hill, 1963). While repetitive for inclusion in a phylogenetic study, such a large-sized animal is necessary in a functional study where size and shape are being explored.

Additional characteristics specific to this study were the space index or the summed linear distance between upper postcanine teeth as a proportion of maxillary toothrow length; and the medial gap between canines at the frontal end of the toothrows when the teeth are occluded, an areal quantity taken from drawings of phyllostomid nectarivores only.

I used principal components analysis to find heavily-loaded characteristics influencing the data. Although good at pointing to major morphological trends, principal com- 
ponents analysis obscures relationships of size and shape of organisms under study. To see how trends in size and shape were distributed among differently-sized organisms of different feeding groups, I regressed each log-transformed measurement against a composite size character that I have used in previous papers (SIZE = sum of the natural logs of condylocanine length, zygomatic breadth, and temporal height; Freeman, 1984, 1988, 1992). This composite character is actually an estimate of head volume, which I believe to be a good estimate of size of bat, and is one that is highly correlated with the first principal component $(r=0.978)$. Unlike using the first principal component as the size character, the composite character will not. change from data set to data set as new material or even fossil material is added. However, on a few occasions I felt other indicators of size were necessary to increase the independence of the independent variable of the regression analyses. In those cases I used area of palate, which is highly correlated with the composite size character (and the first principal component) but is derived independently.

I took areal quantities on nectarivores and megachiropterans using camera lucida drawings, digitizing pad, and sigmaPLot from Jandel. Principal components, regression, and percentile analyses were done with statview (Abacus Concepts). Percentile analysis is a convenient way to show the distribution of a variable and its outliers. These distributions are illustrated by box plots where $10 \%, 25 \%, 50 \%$ (median), $75 \%$ and $90 \%$ of the observations are shown for each feeding group as well as outlying observations, represented by triangles (Fig. 2). A box joins the 25 th to 75 th percentiles.

\section{RESULTS}

The most interesting characteristics are those for which both the regression analyses showed clear separation of dietary groups and those that were also highly loaded on the second principal component. The first principal component explained $85 \%$ of the variation in the data, a phenomenon so common in biological studies that it is often called the size factor. Characteristics heavily loaded on the second component are more related to shape differences among species and here explained $8 \%$ of the variation. Among the most heavily loaded characteristics that also show clear patterns of separation among groups when regressed against the size character are: length from dentary condyle to $\mathrm{M}_{2}$ or $\mathrm{M}_{3}$ (most posterior tooth in lower toothrow), palatal breadth (greatest width across the molars), mediolateral depth of dentary, area of upper molars (includes the molariform $\mathrm{PM}^{4} \mathrm{~s}$ ), and total tooth area. Condylocanine length, length of dentary, length of maxillary toothrow, and area of other upper PMs were heavily loaded on component two but either did not show as clear a pattern of separation among groups in the regression against size or showed no pattern at all (area of other PMs). Further, although the other areal quantities - canines, incisors, $\mathrm{M}^{3}$, and stylar shelf - are not highly loaded on the first two components, they are important quantities to contrast among all feeding groups. Finally, mediolateral width of dentary condyle was not heavily loaded but showed increasing separation of groups when regressed against size and palate and best separation against dentary length. 


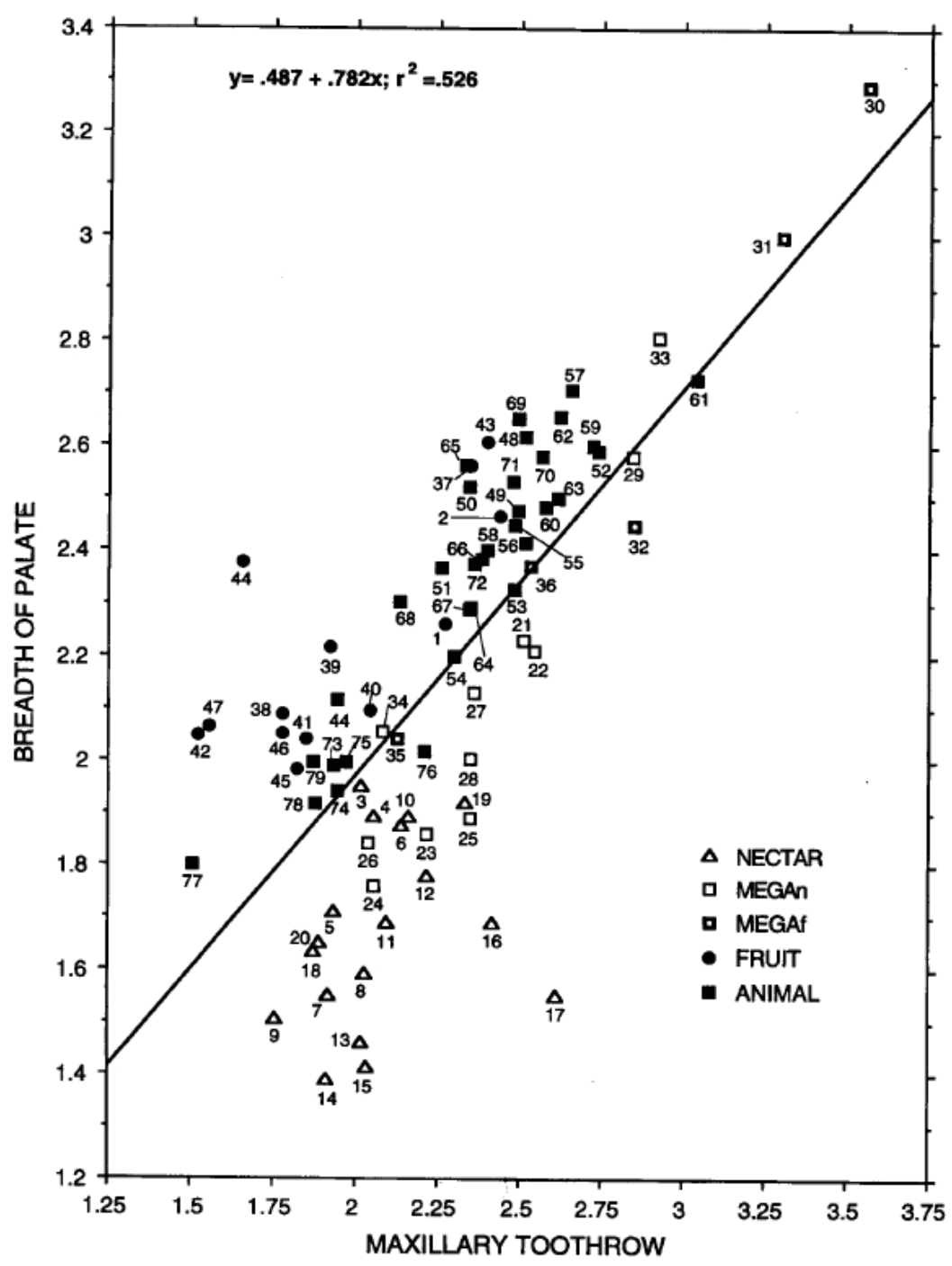

Figure 1. Most animalivorous and frugivorous bats have broader palates (greatest width across molars) relative to toothrow length while phyllostomid nectarivores and many megachiropterans have longer toothrows than wide. Axes are of log-transformed data and bats are identified by numbers listed in Appendix 1.

\section{Cranial features}

The most heavily loaded characteristics on the second principal component are associated with elongation of rostrum and palate. These are: length from condyle to posteriormost lower molar, condylocanine length, dentary length, maxillary toothrow, length from condyle to first lower molar, masseter length, and palatal breadth. However, a simple bivariate plot of palatal breadth versus length of maxillary toothrow summarizes much about the shape of the palate in all bats examined (Fig. 1). Below the regression line are microchiropteran nectarivores as well as many megachiropterans. All Macroglossinae are well below the line. The phyllostomid Musonycteris has 


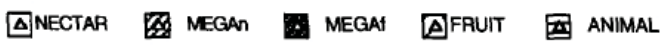
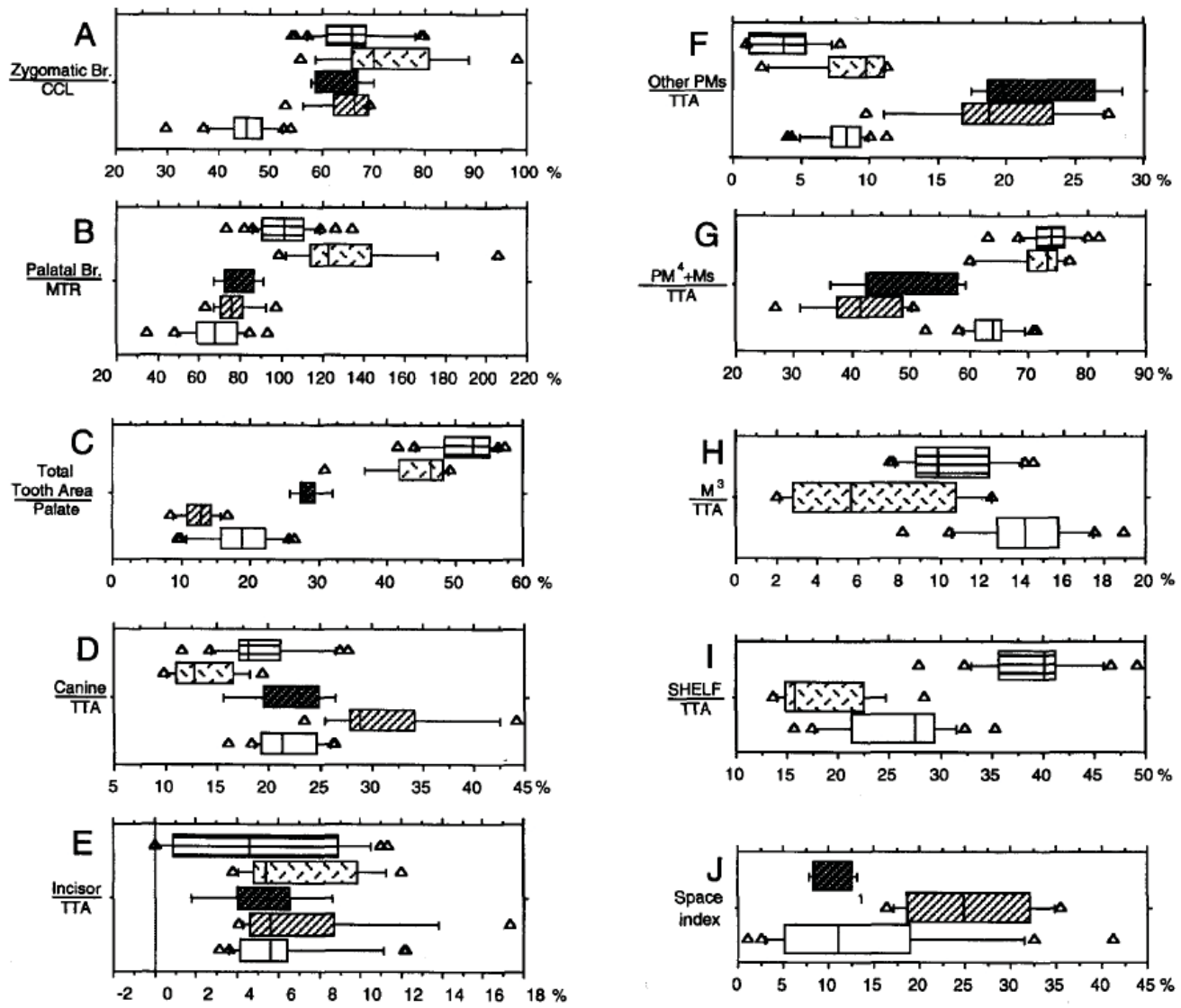

Figure 2. Simple proportions of cranial and dental characteristics in chiropterans illustrated by box plots. Units are the loth, 25th, 50th, 75th, and 90th percentiles where the median and a box enclosing the 25 th -75 th percentiles are easily seen. Triangles represent outlying observations, which better show the distribution of observations and what is affecting the percentiles. Abbreviations are listed in Appendices 1 and 2, and the groups are ordered from bottom to top in each plot for which there is comparable data: microchiropteran nectarivores, megachiropteran nectarivores, megachiropteran frugivores, microchiropteran frugivores, and microchiropteran animalivores.

the narrowest palate. Above the line are all microchiropteran frugivores and nearly all animalivores. Only the phyllostomid insectivore, Macrotus californicus, is below the line, and the three larger animalivores on the line are carnivorous. Palates of microchiropteran frugivores are distinct from all nectarivores and megachiropteran frugivores and can be more than twice as wide as long as in Centurio senex (Fig. 2B).

While megachiropterans are more similar to microchiropteran nectarivores in palatal shape, that is, long and narrow, they are more similar to microchiropteran animalivores and frugivores in shape of the head (zygomatic breadth is $53 \%$ to $70 \%$ of condylocanine length, Fig. 2A). Zygomatic breadth in microchiropteran nectarivores occupies as little as 30\% of condylocanine length in Musonycteris and ranges up to only $54 \%$ in the remaining microchiropteran nectarivorous species. 

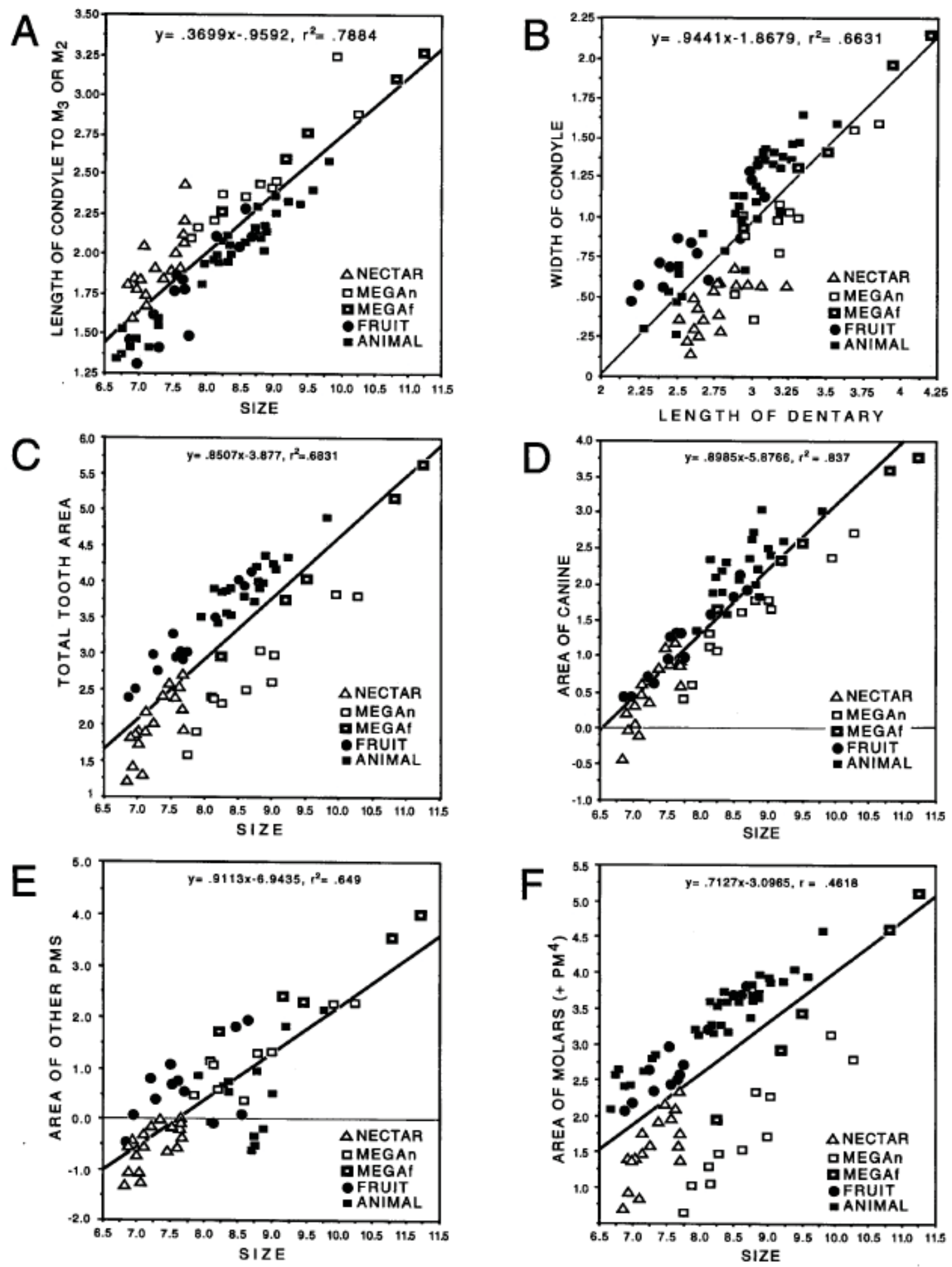

Figure 3. Analyses of relevant linear and areal measurements based on log-transformed data regressed against SIZE or dentary length. SIZE is a composite quantity representing size of the animal and is explained in Methods. 

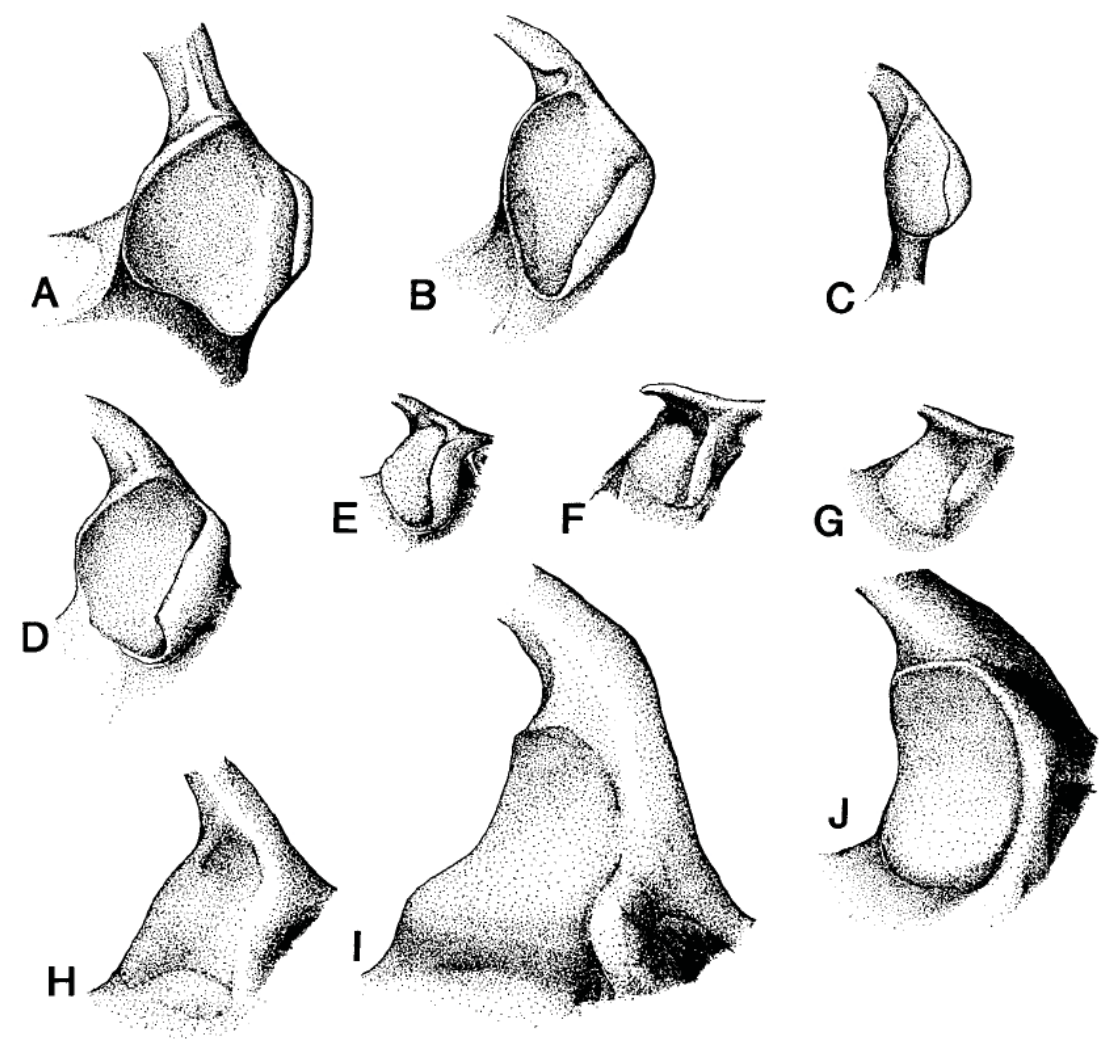

Figure 4. Occlusal view of glenoid fossae of the jaw joints of selected species (not to scale). Fossae of microchiropteran animalivores and frugivores (A. Noctilio leporinus, B. Artibeus jamaicensis, C. Centurio senex, and D. Brachyphylla cavernarum) are raised platforms with distinct borders and prominent postglenoid processes, while those of microchiropteran nectarivores (E. Glossophaga soricina, F. Hylonycteris underwoodi, and G. Choeroniscus intermedius) and megachiropterans (H. Eonycteris spelaea, I. Pteropus scapulatus, and J. Nyctimene major) are less distinct with less prominent postglenoid processes. Fossae of microchiropteran nectarivores also are limited laterally by the ventral extension of the jugal bone. The postglenoid process is quite small in more derived species like Choeroniscus.

Distance from the dentary condyle to the posteriormost lower molar (either $\mathrm{M}^{3}$ or $\mathrm{M}^{2}$ ) is longer in microchiropteran nectarivores and all megachiropterans than in microchiropteran frugivores and animalivores (Fig. 3A). A thinner dentary (mediolateral depth of dentary at first root of $\mathrm{M}_{1}$ ) occurs in most microchiropteran nectarivores and all megachiropterans. The dentary condyles themselves are narrower mediolaterally in most microchiropteran and megachiropteran nectarivores compared to size and palatal area but are best separated when regressed against dentary length (Fig. 3B). A few microchiropterans are below the line as well. Height of condyle relative to the toothrow is negative in several of the megachiropterans, particularly the macroglossines, and at least one of the microchiropteran nectarivores. As noted in a previous study this quantity is not related to changes in size (Freeman, 1988).

Squamosal glenoid fossae of microchiropteran nectarivores differ qualitatively from other bats by having an indistinct platform of articulation, a small post-glenoid process, and a part of the jugal enclosing the fossa laterally (Fig. 4). 


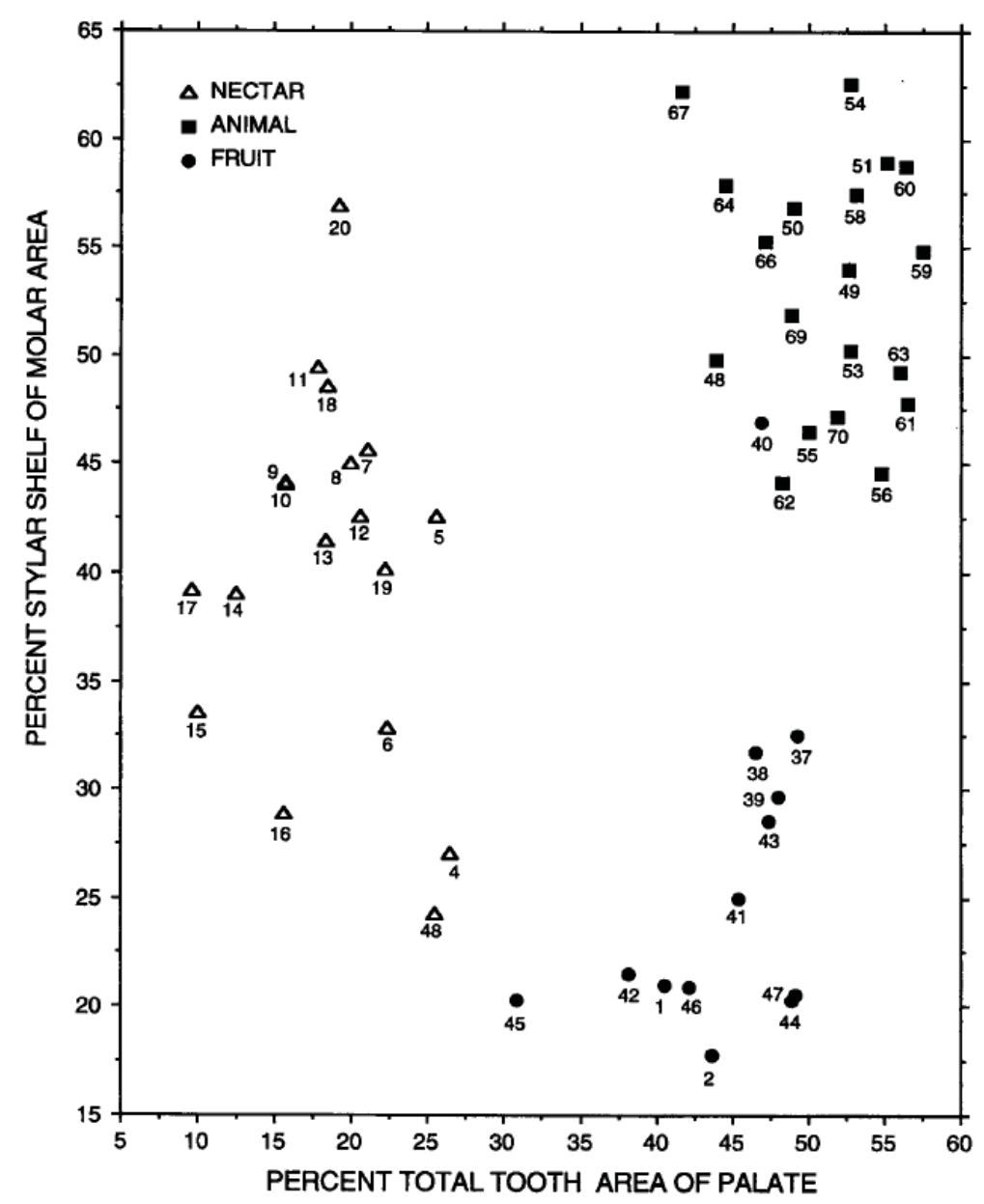

Figure 5. Major contrasts in microchiropteran bats of the relative proportion that teeth occupy of palatal area versus the relative proportion that stylar shelf occupies of molar area. Animalivores have the greatest proportion of the palate occupied by teeth and the greatest proportion of molariform teeth occupied by the raised stylar shelf. Megachiropterans have no identifiable stylar shelf. Numbers are identified in Appen$\operatorname{dix} 1$.

\section{Dental areas}

Microchiropteran nectarivores and megachiropterans have smaller total tooth areas than microchiropteran frugivores and most animalivores (Fig. 3C). Further, relative proportion that tooth area occupies of the palate is nearly non-overlapping. Teeth of animalivorous and frugivorous bats occupy between $38 \%$ and $60 \%$ of the palate while teeth in all nectarivorous species, both micro- and megachiropteran, occupy only 8$26 \%$ (Figs 2C, 5). Frugivorous megachiropterans cluster in a narrow range of 25-32\% and are not only distinctive from nectar-feeding megachiropterans but are also isolated between microchiropteran nectarivores on one hand and microchiropteran frugivores and animalivores on the other.

Proportions that each kind of tooth occupies of tooth area are in Fig. 2. Canines occupy as much as $44 \%$ of tooth area in megachiropteran nectarivores, notably Notopteris and Melonycteris, and range from 23\% to 44\% (Fig. 2D). All other bats have less 
than 28\%. Microchiropteran nectarivores have larger canines than microchiropteran frugivores relative to total tooth area, but in actual size micro- and megachiropteran nectarivores have some of the smallest canines (Figs 2D, 3D). Relative canine area in microchiropteran animalivores is within the range of other bats, but in actual size these are some of the largest canines of any bat here (Figs 2D, 3D). Megachiropteran frugivores have a similar relative canine area as microchiropteran nectarivores, but actual size of canines in megachiropteran frugivores are larger than canines in megachiropteran nectarivores and closer to the regression line (Fig. 3D).

Incisors occupy $12 \%$ or less of tooth area in all microchiropterans and most megachiropterans. Only Syconycteris australis, a megachiropteran nectarivore, has more at $17 \%$ (Fig. 2E). There is no clear pattern associated with size.

Megachiropteran bats have large non-molariform premolars that occupy $10-28 \%$ of total tooth area, and most are from $16 \%$ to $28 \%$ (Fig. $2 \mathrm{~F}$ ). Two outlying megachiropteran nectarivores have premolars occupying the least amount of total tooth area and overlap the microchiropterans. Animalivorous bats have the least area occupied by premolars, from 0 to $8 \%$, while microchiropteran frugivores and microchiropteran nectarivores have $11 \%$ or less. In actual size, the largest non-molariform premolars occur in both megachiropteran and microchiropteran frugivores (Fig. 3E). Two microchiropteran frugivores below the regression line are species of Brachyphylla.

Relative to total tooth area, microchiropterans have larger molariform areas than megachiropterans; and with the exception of Musonycteris and Leptonycteris, two microchiropteran nectarivores, there is no overlap (Fig. 2G). Among microchiroptera the largest molariform teeth occur in animalivores, from $62 \%$ to $82 \%$ of total tooth area; frugivores from $60 \%$ to $77 \%$; and phyllostomid nectarivores from $52 \%$ to $72 \%$. Megachiroptera range from $28 \%$ to $59 \%$, with the median of frugivorous species slightly greater than that of nectarivorous species. In actual size, however, molariform teeth are dramatically smaller in microchiropteran nectarivores and megachiropterans, but megachiropteran frugivores have larger teeth than megachiropteran nectarivores (Fig. $3 \mathrm{~F})$. In part the position of species below the regression line is because megachiropterans have no $\mathrm{M}^{3}$. Most microchiropteran nectarivores below the line have $\mathrm{M}^{3}$, and that tooth is included in the measurement, but the critical point is that these bats simply have diminutive molariform teeth.

For those species of microchiropterans with $\mathrm{M}^{3}$ present, the tooth is relatively large in animalivores and phyllostomid nectarivores (8-14\% and 8-19\%, respectively) and smaller in frugivores where it is never more than $6 \%$ of total tooth area (Fig. $2 \mathrm{H}$ ). Although medians are separated there is overlap in the ranges of all three microchiropteran groups. There is no clear pattern associated with size.

The proportion that the stylar itself occupies of total tooth area in microchiropteran bats is greatest in animalivores, which ranges from $28 \%$ to $49 \%$. The range for nectarivorous bats is $14-35 \%$, but the median is well- separated from both animalivores and frugivores (Fig. 21). Frugivores have the smallest stylar shelves relative to total tooth area. There is no clear pattern associated with size. Contrasts in relative area that stylar shelf occupies of molars and the proportion of tooth-bearing palate among microchiropterans are summarized in Figure 5. Further, the proportion that molariform teeth and non-molariform teeth occupy of the palate in both Micro- and Megachiropteran are summarized in Figure 6. 


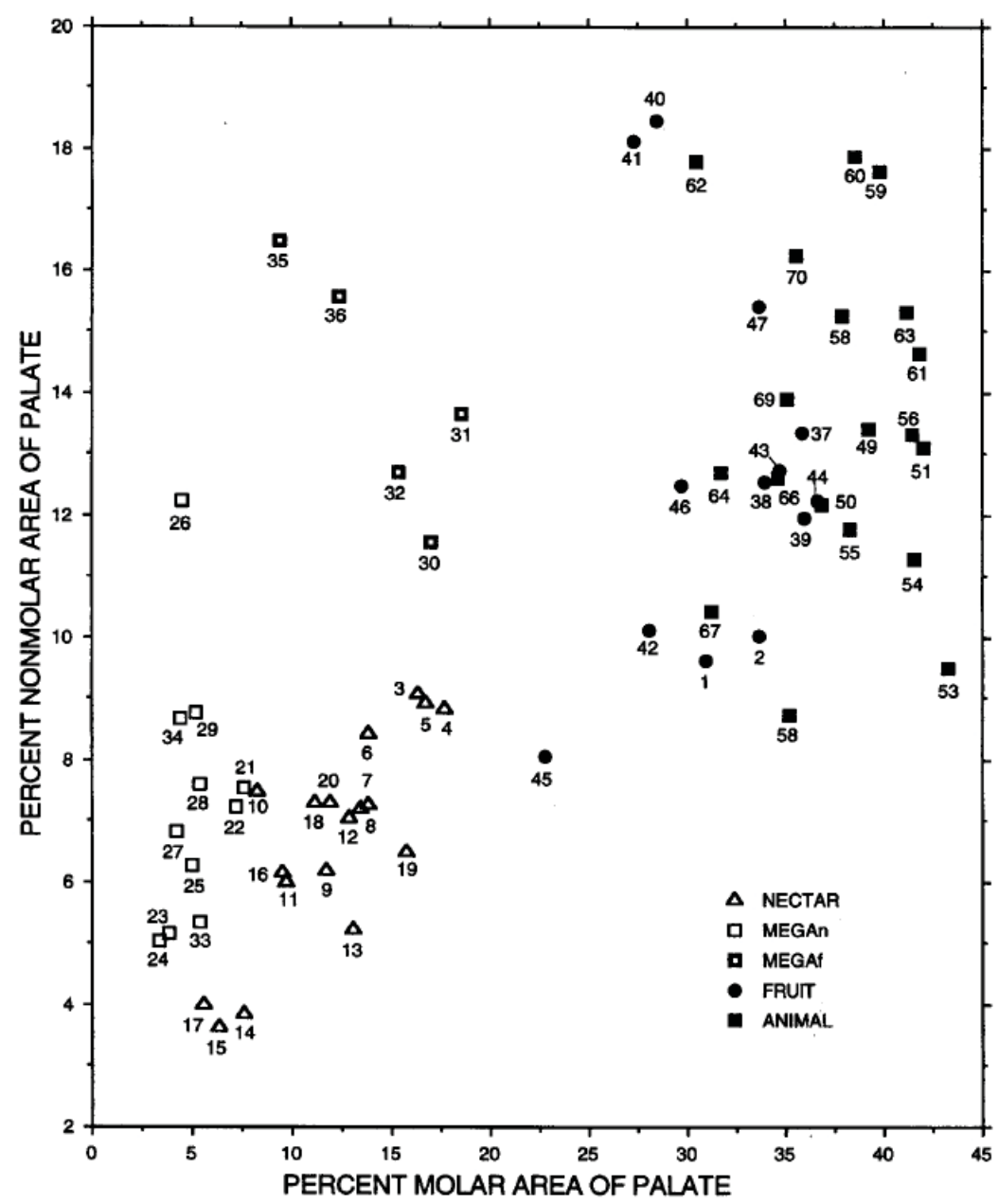

Figure 6. Relative molar (includes $\mathrm{PM}^{4}$ ) versus non-molar (incisors, canines, and nonmolariform premolars) areas of the palate for all feeding groups. Microchiropteran animalivores and frugivores including species of Artibeus (37, 38, 39, and 43) and Centurio (44), which lack $\mathrm{M}^{3}$, have greater molariform areas than do microchiropteran nectarivores and megachiropterans. Megachiropterans, Lichonycteris (9), and Leptonycteris (10) lack $\mathrm{M}^{3}$ as does Ectophylla (45). Megachiropteran frugivores have large anterior premolars, while the megachiropteran nectarivore, Syconycteris, has large incisors. Numbers are identified in Appendix 1.

The space index, which is the sum of linear space between upper postcanine teeth divided by toothrow length, was calculated to show the relative proportion of toothrow not occupied by teeth. The index in microchiropteran nectarivores ranges from $1.0 \%$ in Erophylla to $41.2 \%$ in Musonycteris with the frugivore (?) Ectophylla at $8.2 \%$ (Figs 2J, 7). Among megachiropterans, frugivorous forms have the lowest percentages, from $7.9 \%$ to $13.3 \%$, followed by nectarivorous species from Eonycteris spelea at $16.3 \%$ to Scotonycteris zenkeri at $35.5 \%$.

Microchiropteran nectarivores with frontal gaps greater than $1.25 \mathrm{~mm}^{2}$ were found in Hylonycteris (at one extreme), Musonycteris, Anoura, Lichonycteris, Choeronycteris, and Choeroniscus (at the other extreme of over $2.25 \mathrm{~mm}^{2}$, Fig. 7). Remaining species, from Leptonycteris to Phyllonycteris and Erophylla, had $0.5 \mathrm{~mm}^{2}$ or less (Fig. 7). 


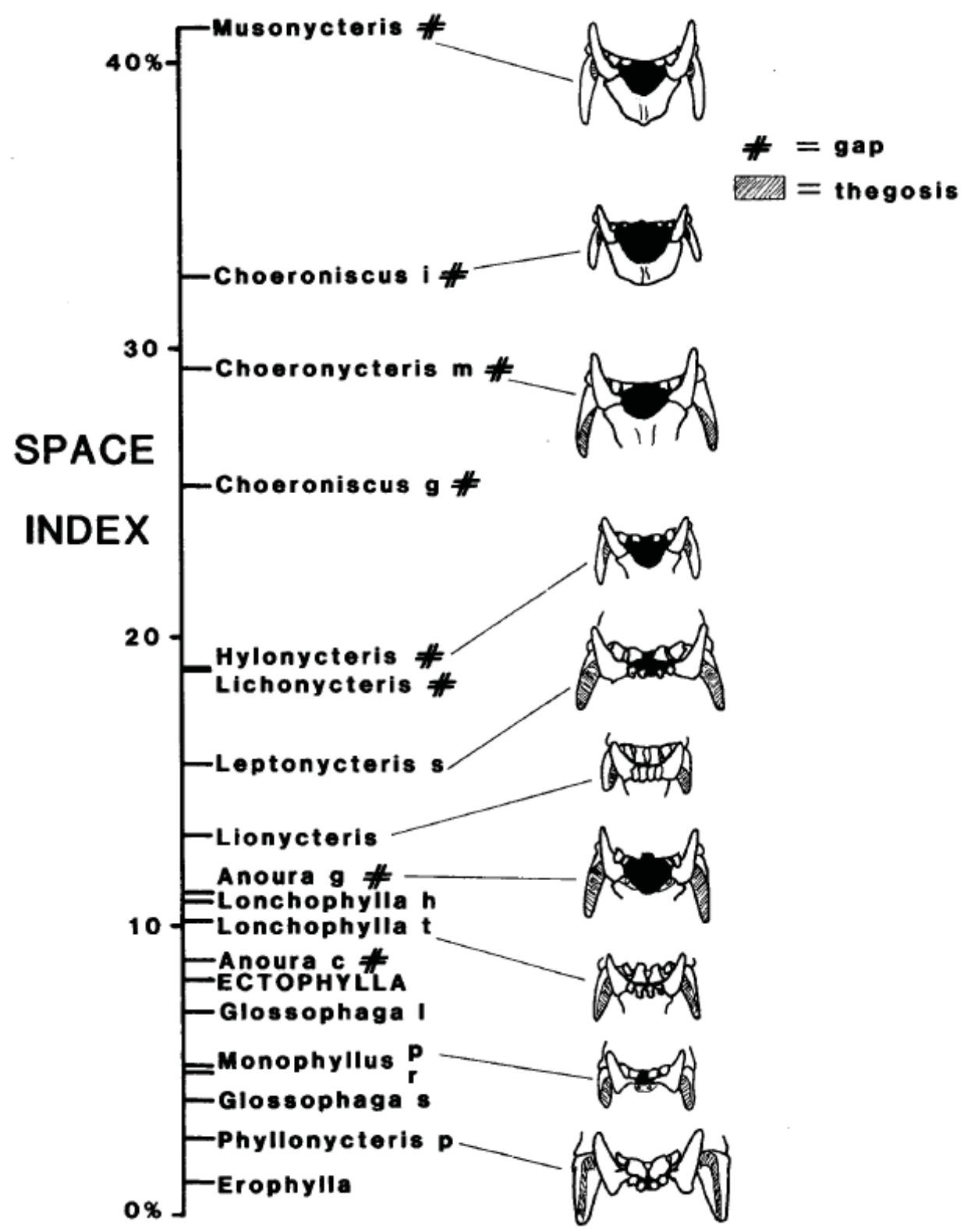

Figure 7. Microchiropteran nectarivores and Ectophylla are ranked according to total space between upper teeth over length of maxillary toothrow (Space Index). Added to this ranking is a frontal view of the occluded skull showing the medial, frontal gap between canines, loss or presence of lower incisors, and pattern of thegosis (wear caused by opposing lower canines) on the anterior surface of the upper canines. Bats at the bottom of the ranking are probably more generalized feeders, while bats at the top may be more obligate nectarivores.

\section{DISCUSSION}

Among microchiropterans certain animalivores (notably Noctilio, Cheiromeles, Scotophilus, and Saccolaimus) and many of the frugivores have especially wide faces. I attributed a wide face to eating hard items in the animalivores and taking plugs from 
or transporting large fruits in frugivores (Freeman, 1984, 1988). In these wide-faced animals teeth are closer to the fulcrum of the jaw lever arm, volume of masseter increases, and strength of bite is enhanced (Greaves, 1985). Microchiropteran nectarivores are opposite this extreme in that they have long, narrow heads. Where zygomatic width can be as much as $80-98 \%$ of condylocanine length in frugivorous and insectivorous microchiropterans, that width is as little as $30 \%$ in nectarivorous microchiropterans. Narrow zygomatic widths mean less volume for jaw musculature and decreased strength of bite. Strength of bite would also be decreased by the teeth being further from the fulcrum of the jaw lever arm. Interestingly, the greatest extremes in diversity of the shape of the face in this study are confamilials, the pug-faced Centurio and the long-snouted Musonycteris (Fig. 1).

Megachiropterans do not have the same long, narrow head as microchiropteran nectarivores because zygomatic breadth is much greater, but both nectarivorous and frugivorous megachiropterans do have the same narrow palate (width across the molars; Fig. 2A, B). As a result megachiropterans have greater volume of jaw-closing musculature, which Storch (1968), who dissected and quantified jaw musculature, found to be true. In this aspect megachiropteran nectar-feeders with only moderately long rostra are unlike microchiropteran nectar-feeders. With the elongate rostra in microchiropteran nectarivores and enlarged tongue, there is a concomitant decrease in importance of jaw-closing muscles-particularly the masseter-that would otherwise occupy and enlarge the space between the zygoma and the lateral side of the mandible. Teeth become less important in feeding and need not be close to the fulcrum of the jaw mechanism. Freed from the constraint to increase biting power as well as responding to an enlarged tongue, teeth become diminutive and separated from each other as the jaw lengthens. Elongation is probably in response to selection for a longer tongue and larger associated muscles for protrusion and retraction. Megachiropterans have a narrow palate like the microchiropteran nectarivores but retain a wider head like other microchiropterans. The difference may be dietary. The extreme specialization seen in microchiropteran nectarivores may indicate a more obligatory diet of nectar, while the wider face of megachiropterans may indicate a more generalized diet of nectar and fruit. Megachiropteran nectarivores would not lose all of their jaw musculature if even a small percentage of fruit is in the diet. Perhaps the narrow plate is a required trait for effective nectar-feeding and has some close functional relationship with an enlarged tongue, but both megachiropteran nectarivores and megachiropteran frugivores have narrow palates.

Megachiropterans and microchiropteran nectarivores share a similar, longer distance from the last lower molar to the dentary condyle, the fulcrum of the jaw articulation. This distance is shorter in microchiropteran frugivores and animalivores (Fig. $3 \mathrm{~A})$. Greater distance from the fulcrum means less work is being done at the back of the toothrow. Typically molars in mammals are lost from back to front through time. The third upper molar is present in all the animalivores although, as noted in previous papers, the cusp pattern on $\mathrm{M}^{3}$ can vary among insectivores with presence or absence of the premetacrista, the most posterior cusp on the ectoloph (Freeman, 1979). In cases where the premetacrista is present, the ectoloph has an upside down 
$\mathrm{N}$-shape, and where it is absent or abbreviated the ectoloph is V-shaped. Molossids with the V-shaped pattern also have a more anterior attachment on the zygoma for the origin of the masseter. As a result the muscle attachment is anterior to and completely overlaps $\mathrm{M}^{3}$ (Freeman, 1979: fig. 3). In contrast, the anterior margin of the masseter only just reaches $\mathrm{M}^{3}$ and does not overlap in molossids with the N-shaped pattern. In the former the abbreviated tooth is closer to the fulcrum, has better mechanical advantage, and probably functions in eating harder items than the latter (Freeman, 1981). Evolutionarily, the abbreviated $\mathrm{M}^{3}$ is still an important tooth on the toothrow even though anterior molars may be larger or the entire toothrow is closer to the fulcrum. Short-snouted, wide-faced individuals should have better mechanical advantage for these reasons as well as for reasons of increased musculature. Noctilio is unusual because it has both a short snout and an N-shaped ectoloph on $\mathrm{M}^{3}$ (Freeman, 1984: fig. 2). The anterior margin of the masseter also overlaps $\mathrm{M}^{3}$. Noctilio needs both power (short distance from fulcrum and increased musculature) and grip (lengthened ectoloph) for foods it eats-fish, insects, and fiddler crab claws - all of which are captured first by feet then by teeth while flying (Brooke, 1994). All the carnivorous species in this study-Megaderma, Cardioderma, Nycteris, Vampyrum, Chrotopterus, Trachops and even the more omnivorous Phyllostomus hastatus - have abbreviated but well-developed $\mathrm{M}^{3} \mathrm{~s}$. In carnivorous bats the anterior molars have enlarged to accommodate the lengthened metacristae of $\mathrm{M}^{1}$ and $\mathrm{M}^{2}$ for shearing meat (Freeman, 1984).

Among microchiropteran frugivores three genera have lost $\mathrm{M}^{3}$ (Artibeus, Centurio, and Ectophylla). Anterior molars have become large, wide-basined teeth for crushing fruit. The first upper molar in Artibeus contributes 40\% of the toothrow's molariform area (Freeman, 1988), and the distance from the posterior margin of the lower molars to the fulcrum of the jaw joint is the same as in animalivorous species (Fig. 3A).

With exception of Lichonycteris and Leptonycteris where $\mathrm{M}^{3}$ is absent, microchiropteran nectarivores not only retain an $\mathrm{N}$-shaped $\mathrm{M}^{3}$ (although only a wavy, labial rim in some), but the end of the toothrow is farther from the fulcrum and jaw musculature is decreased. The anterior margin of the masseter is well posterior of the last upper molar in 12 of the species, just meets the molar in two, and overlaps a portion of the molar in four. Cheekteeth are diminutive. Not only is there a lack of emphasis at the back of the toothrow but on all postcanine teeth as well.

Loss or diminution of teeth in long-snouted, long-tongued mammals is not uncommon, and has occurred most notably in myrmecophageous mammals like aardvarks, armadillos, pangolins, true anteaters, and echidnas. Perhaps more relevant to this discussion are the dentate carnivorans Octocyon, the bat-eared fox, and Proteles, and aardwolf. Otocyon has insectivorous teeth, no carnassial pair, well-developed $\mathrm{M}^{3}$ with premetacrista, elongated jaws with space between the premolars, and respectable canines. It is known to be insectivorous. Proteles has no upper or lower molars, diminutive and vestigial premolars separated by spaces, respectable canines, and the anterior margin of the masseter is posterior to the last upper tooth. Diet of Proteles is termites and the need for postcanine teeth is de-emphasized. Kruuk \& Sands (1972) think this diminution is related to the "very broad tongue" that takes large patches 
of worker termites (and substantial quantities of grit) swiftly from the surface before too many soldier termites with their foul secretions arrive to make the mouthful distasteful.

No megachiropteran has $\mathrm{M}^{3}$ and, like microchiropteran nectarivores, distance from the fulcrum to the most posterior lower molar is longer than in microchiropteran frugivores and animalivores. But while nectarivorous megachiropterans have diminutive postcanine teeth indicating de-emphasis on all teeth, frugivorous species have especially robust premolars at the anterior end of the toothrow. The anterior margin of the masseter in most of the megachiropteran nectarivores is posterior to the last upper molar, but the margin overlaps the molar in megachiropteran frugivores, which I believe increases bite force.

Animalivorous bats not only have larger teeth on the palate, but those teeth have the greatest amount of space-up to $62 \%$ - dedicated to the raised stylar shelf (Freeman, 1988: fig. 5; Fig. 5 this paper). Microchiropteran frugivores have large teeth, but most of their molar area is occupied by basin. The tiny stylar shelves are pushed to the outer rim of the dental arcade and occupy only $18-32 \%$ of molars. The omnivorous Carollia (Fig. 5, number 40) has proportions more similar to animalivorous bats than to frugivorous. Microchiropteran nectarivores have only between a tenth and a quarter of the palate dedicated to teeth, but the ratio of stylar shelf to molar area is within the range, though not as extreme, as that found in frugivorous and animalivorous bats. While these proportions may be similar, teeth in nectarivorous bats are some of the smallest (Fig. 3). Megachiropterans are not in Fig. 5 because there are no comparable stylar shelves, but teeth of megachiropteran nectarivores occupy only $9-18 \%$ of the palate, which is a distinctly smaller portion of the palate than the larger teeth of megachiropteran frugivorous species (Fig. 2C).

Modifications of the ancestral dilambdodont pattern in upper molars of microchiropterans include: lengthening and realigning the metastylar ridge anteroposteriorly in carnivorous species to produce significant blades for shearing meat (Freeman, 1984); pushing paracone and metacone to the labial edges of the tooth leaving only a raised, wavy rim bordering a large basin in frugivorous microchiropterans (except perhaps Brachyphylla, Griffiths, 1985) for crushing fruits (Freeman, 1988); and simply reducing the size of the teeth bearing the unmodified dilambdodont pattern in nectarivorous microchiropterans (Fig. 5). All three of these conditions - animalivory, frugivory, and nectarivory-seem independently derived from an unspecialized insectivorous microchiropteran ancestor. Brachyphylla shows an interesting melange of characteristics that is discussed later.

Proportions of the palate, not total tooth area, occupied by molar and non-molar teeth of both micro-and megachiropteran are summarized in Figure 6. Microchiropteran frugivores (including those without $\mathrm{M}^{3}$ ) and animalivores have greater molar areas than microchiropteran nectarivores and megachiropterans. Except for Ectophylla alba, these two groups are well separated (Fig. 6, number 45). Ectophylla has no $\mathrm{M}^{3}$, has the least molar area relative to the palate of any frugivore, has measurable space between cheek teeth in the upper toothrow, and poorly known food habits. Nectar may well be part of its diet. Molariform teeth of six carnivorous bats-Chrotopterus auri- 
tus, Vampyrum spectrum, Nycteris grandis, Cardioderma cor, and Megaderma lyraand the insectivorous Rhinolophus rufus occupy the greatest portion of the palate (at nearly $45 \%$, Fig. 6). Why teeth should occupy a large portion of the palate must have something to do with the rather substantial job of chopping through and processing insect prey or crushing plugs of fruits (see also Freeman, 1988). Consumption of insects is often done on the wing, and since it would be an advantage to dispatch struggling prey rapidly, having a palate that is two-thirds teeth may be the best arrangement for the mouth.

Small-molared bats that have the greatest area dedicated to non-molariform teeth are megachiropteran frugivores and the macroglossine Syconycteris, a megachiropteran nectarivore (Fig. 6). The latter has the smallest percentage of molariform teeth $(5 \%)$ but has well-developed incisors and canines. Robust non-molariform premolars, are the reason megachiropteran frugivores are distinctive. Teeth of megachiropteran frugivores are the largest of any bat in actual size, but these are borne on even larger-sized palates and as a result occupy a smaller portion of the palate than teeth in microchiropteran animalivorous and frugivorous bats. What the difference is in how megachiropterans take bites and how much food is eaten in one bite might well affect this tooth/palate relationship. Might this behavior also affect the shape of the head? And although they have well-developed non-molariform teeth they do not have the wide, parabolically-arched palate seen in more extreme microchiropteran frugivores. I speculated that a wide mouth would yield a wide grip for the better transport of fruit in microchiropteran frugivores (Freeman, 1988). Emphasis on anterior premolars in Megachiroptera was noticed by Slaughter (1970) who pointed to the molarization of $\mathrm{PM}_{3}$ as another unique characteristic and, among all other eutherians, occurred only in some ungulates. Koopman \& MacIntyre (1980) observed that occlusion in megachiropterans occurred only at the front of the mouth and that in the process of specializing on fruit and nectar upper and lower molars do not meet. The latter comment was made in the context to why there is difficulty in tracing cusp homologies between micro-and megachiropterans, but I believe there is a quantitative difference in the functional importance of premolars particularly in megachiropteran frugivores and perhaps in all frugivorous bats. Microchiropteran frugivores also have larger anterior teeth (Freeman, 1988). Although some species lack $\mathrm{M}^{3}$ these bats generally have large $\mathrm{M}^{1} \mathrm{~s}$, larger non-molariform premolars, and smaller canines. Megachiropteran frugivores have large canines and large non-molariform premolars, but smaller molariform areas that make them different from other bats (Figs 2, 6).

Except for Syconcyteris micro- and megachiropteran nectarivorous bats, have the smallest teeth, both molariform and non-molariform, on the palate (Fig. 6). In the most extreme cases, molariform teeth occupy only $5 \%$ of the palate and non-molariform teeth add only an additional $4 \%$. Such small amounts are proof of the de-emphasis of teeth in nectarivorous bats. Three species of microchiropteran nectarivores with the greatest molariform areas (15-17\%) are Erophylla sezekorni, Phyllonycteris poeyi and Glossophaga soricina. Brachyphylla nana and B. cavernarum, species that may have a close phylogenetic relationship with Erophylla and Phyllonycteris (Griffiths, 
1982), have a molariform area between $25 \%$ and $30 \%$ and are more similar to frugivores and animalivores.

Microchiropteran omnivores (Phyllostomus hastatus, Carollia perspicillata, Sturnira lilium; Freeman, 1988) have only $30 \%$ of the palate occupied by molariform teeth but also have the highest proportion occupied by non-molariform teeth (18\%). Summed, nearly half of the palatal area is teeth, but the composition of non-molariform teeth to molariform teeth is different from more insectivorous or carnivorous species.

Hill \& Smith (1984) mentioned that upper incisors of most nectarivores are usually enlarged and procumbent and that they are used to break open nectar glands at the base of a flower's corolla. Medians of the relative size of incisors are similar among all feeding groups and while there are one or two outlying nectarivores that have larger incisors (Fig. 2E), the most derived microchiropteran nectarivores have reduced upper incisors (Fig. 7). Lower incisors are reduced in size and number in both micro- and megachiropteran nectarivores, but among the former reductions are extreme. Medial, frontal gaps that appear between the canines must be the result of increased size and activity of the tongue. Selection for an unhindered path into the mouth during feeding would be important. It is here I think the canines are playing an even more interesting role than incisors in nectar-feeding.

Upper canines in microchiropteran nectarivores are relatively large, especially compared with microchiropteran frugivores. This relatively large size is surprising given the diminutive nature of the cheek teeth. In addition, canines of microchiropteran nectarivores have various patterns of heavy wear on their anterior surface where the lower tooth passes when the jaws occlude Tooth-on-tooth wear is called thegosis (Every, 1965, 1970; Freeman, 1992). Although samples are small, there is a tendency for the entire face of the canine to be worn in those bats without a frontal gap and a smaller, usually cingular, patch of wear in those bats with large gaps (Fig. 7). Toothon-tooth wear could result from bracing of lower teeth on upper to support the jaw during the rapid movement of the tongue at feeding. The pull of the temporalis muscle, the jaw-closing muscle primarily responsible for opposing depressive forces at the anterior end of the skull, and possibly the masseter, would hold the lower canines against the anterior surface of the upper canines while the long tongue extends. For those nectarivorous bats without a frontal gap and with incisors in the tongue's path, the mouth has to be held open slightly while the tongue protrudes and retracts. The result of holding open the jaws is that the full length of the anterior face of the upper canine is rubbed by the lower canine to let the tongue work while avoiding the incisors. For those bats with a frontal gap the small patch of thegosed wear at the cingula of the upper canines indicates bracing is still occurring even though the teeth are occluded during feeding.

All nectarivorous bats here, whether micro- or megachiropteran, have fused mandibulae. Beecher (1979) thinks fusion occurs to counteract vertical forces at the front of the jaw. But it may also be that when there is less precise registration of cheek teeth and less need for minute adjustments at the symphysis, mobility decreases to the point of fusion (M. Joeckel, pers. comm.). Scapino (1965) found mobile, unfused symphy- 
ses in carnivorans that need precise registration. Registration of teeth may not be as precise or may be non-existent in megachiropterans and in microchiropteran nectarivores and frugivores, and all of these bats have fused mandibulae. Animalivorous bats have little of no wear on the anterior face of the canine, even in older specimens (Freeman, 1992; unpublished data), nor do they have fused mandibulae. These are bats that need much precision for the dilambdodont pattern to mesh properly with the lower teeth. Finally, Desmodus is a sanguinivorous bat that also uses its tongue in feeding. The entire length of the anterior face of the upper canines of Desmodus is heavily thegosed, the upper incisors are well developed, and the mandibles of this short-faced bat are immobile but not completely fused. The entirely thegosed canines may be indicative of bracing in the jaws while the tongue is actively lapping blood.

Ranking microchiropteran nectarivores with little space between teeth to those with much space between teeth are in Fig. 7. The more elongated the rostrum the greater the amount of space relative to the maxillary toothrow, which I interpret as a simple index of nectarivory for microchiropterans. Further, when representative bats with frontal gaps between canines in the occluded skull and patterns of thegosis on the upper canines are added, the index is even more significant. With exception of the two species of Anoura, largest frontal gaps and greatest loss of incisors are in those species with the greatest amount of space between upper cheek teeth (Fig. 7). Because upper teeth of microchiropteran frugivores fit together tightly (Freeman, 1988), I think Erophylla may have a more generalized diet while bats like Choeronycteris and Musonycteris with well-separated teeth may be more obligate nectarivores.

Megachiropterans also have measurable space between upper cheek teeth (Fig. 25). Frugivorous species have the least space and nectarivorous species the most, but none of the megachiropterans have frontal gaps and one or two upper and lower incisors are always present. Canines in all but two megachiropterans here are worn by thegosisthe frugivorous Harpyionycteris and the nectarivorous Scotonycteris. An increased volume of masseter muscle, a jaw-closing muscle, might enable megachiropterans to hold their jaws slightly apart with lower canines braced against upper while the tongue works. Whether space between teeth tells anything about nectarivory in Megachiroptera is an interesting question. Megachiropteran food habits are not well known and an obligatory diet of fruit or nectar may be less well- demarcated (Marshall, 1983, 1985). Marshall maintains that most megachiropterans "are catholic in their choice of food, and most plants are visited by a diversity of bats (1985: 351)". One could reason that frugivorous species have space between the teeth because a certain portion of the diet is nectar, the tongue has to be large for the successful consumption of nectar, and space forms between the teeth as a result. This explanation might also apply to a microchiropteran like Phyllonycteris, a bat that is not as specialized for nectarivory as other phyllostomids, has space between the teeth, and has molars superficially resembling megachiropteran molars (Miller, 1907; Koopman \& MacIntyre, 1980). Not knowing how megachiropterans evolved from a presumably insectivorous ancestor confounds any explanation of function, and this is especially true in frugivorous and herbivorous mammals where the occlusal relationship between upper and lower teeth is lost (Koopman \& MacIntyre, 1980). However, because there are many features shared by 
megachiropteran nectarivores and frugivores, I believe one is derived from the other and not independently from an insectivorous ancestor as microchiropterans probably evolved. The traditional view is that nectarivorous megachiropterans are derived from frugivorous forms probably because of the diminution of teeth.

In a different vein because bracing of canines at the front of the jaw of nectarivorous forms has to be supported at the fulcrum of the jaw lever system in back, I examined dentary condyles and glenoid fossae. All microchiropteran nectarivores and many megachiropterans here have dentary condyles that are shorter than condyles of microchiropteran frugivores and animalivores with the same length of dentary (Fig. 3B). Of the former group, megachiropteran frugivorous have the longest condyles. At the same time glenoid fossae in insectivorous microchiropterans are well-defined, sub-horizontal, bony platforms with well-developed, orthogonal, postglenoid processes (Freeman, 1979: fig. 1). This same configuration can be seen in microchiropteran carnivores and frugivores as well (Fig. 4A, B, C, D). In some species the ventral tip of the postglenoid curls around anteriorly and is reminiscent of that process in terrestrial carnivorans where a well-developed process can prevent condylar disarticulation (Fig. 4D). This process braces the mandible during the capture of prey with the canines by opposing the backward pull of the temporal muscles. Glenoid fossae in nectarivorous microchiropterans are not well-defined platforms, and postglenoid processes are reduced in several species and to only a small bump in Choeroniscus (Fig. 4G). Further, in several species a portion of the jugal bone at the posterior bend in the zygoma extends ventrally to form a cup-like process that seems to prevent lateral movement of the condyle in the fossa. This cupping may cause reduction in the condyle itself, and the most extreme cupping can be seen in Anoura and Hylonycteris (Fig. 4F). In megachiropterans the typical fossa is not a defined platform but simply a flattened indentation on the inferior side of the jugal (Fig. 4H, I, J). There is no obvious difference between nectarivorous and frugivorous species. Generally, the flattened area is inclined anteroposteriorly where the more ventral posterior edge may serve the same function as the postglenoid process (that is, to stop the dentary from dislocating and invading ear space).

Smaller condyles and less prominent processes at the posterior edge of the glenoid may be a functionally significant occurrence that goes along with elongated jaws, relatively large canines, thegosis and bracing of the lower jaw at the canines in microchiropteran nectarivory. Elongation may also cause a thinner mediolateral thickness of the dentary at $\mathrm{M}$, to make a more gracile mandible. Megachiropterans share some of these same characteristics but also have greater volume for jaw musculature at the zygomata, and frugivorous species have well-developed teeth. Without a larger sample and greater knowledge of diet, I do not include megachiropterans in the same microchiropteran generalization, perhaps because they do not seem as specialized as microchiropteran nectarivores. Many of the megachiropteran nectarivores also have dentary condyles that are equal with or below the level of the toothrow. Storch (1968) intimated that the lowered joint may enhance swallowing, and, I presume, aid in eating fruit or nectar. However, the level of the condyle and its function in chewing has been the source of much discussion (Freeman, 1979; 1984; Greaves, 1980; Hildebrand, 1988) and not one that I address here. 
Brachyphylla is a perplexing genus both phylogenetically (Griffiths, 1982; 1985) and functionally. Diet indicates frugivory, but insects and pollen are also present (Gardner, 1977). Species in this genus are similar to microchiropteran frugivores in several characteristics - zygomatic breadth over length of toothrow, total tooth area of palate, molariform area of total tooth area, and the lack of space between the teethbut are more like nectarivores in area for non-molariform premolars and length from the last lower molar to the dentary condyle. Further, the canines have secondary cusps as in some carnivorous bats (Freeman, 1992), and the postglenoid process curls anteriorly as in some terrestrial carnivorans (Fig. 4A), which may help hold the condyle more securely in the fossa. Finally, there is some question as to homology of cusps on molars in Brachyphylla (Slaughter, 1970; Griffiths, 1985). Species of Brachyphylla must be generalists in what they eat and have a propensity toward fruit, but such an interesting melange of morphological features could mean an as-yet-undiscovered food in the diet or an unknown feeding behavior. Although frugivory is indicated, could these be nectarivores that evolved bigger teeth, or nectarivores that simply take the whole flower and not just nectar? Are they omnivorous and difficult to categorize? Because brachyphyllid tongues are not elongated and not vascularized as in phyllonycterids or glossophagids, Griffiths (1985) suspects a specialized reversal and agrees with Pine (Silva Taboada \& Pine, 1969) and Brachyphylla fills a frugivore niche in the Antilles not filled by other frugivores.

There are many convergent features between nectarivorous bats and several mammalian myrmecophages (Smith \& Redford, 1990). Typical of these long-snouted mammals-including Tachyglossus, Oycteropus, Dasypus, Tamandua, Myrmecophaga, and Chaetophractus - nectarivorous bats exhibit diminution of teeth, elongation of rostrum, more gracile dentaries, and enlargement of tongue. However, unlike those mammals these bats retain a fused mandibular symphysis and well-developed canine teeth. These two characteristics are shared by both micro- and megachiropterans. Interestingly, the termite-eating Aoteles (Hyaenidae) also has small teeth separated by spaces, large canines, fused mandibulae, and thegosed upper canines.

Finally, the structure of the elongated tongue has been likened to a muscular hydrostat, a muscular organ typically lacking in skeletal support (Kier \& Smith, 1985). The basic principle of a hydrostat is that its volume is constant. Elongation is produced by a contraction of cross-sectional muscles while shortening is produced by a contraction of the longitudinal muscles. However, most of the hydrostats studied seem to be structures that involve a single or only a few protrusile events (Kier \& Smith, 1985; Smith \& Kier, 1989). While the hydrostat idea sounds feasible for frog and chameleon tongues, elephant trunks, echidna and other anteater tongues as well as a variety of invertebrate parts for feeding or locomotion, I question whether the muscular hydrostatic model can completely explain the rapidly repeating, protrusionretraction phenomenon that occurs in the typical feeding bout of a microchiropteran nectarivorous bat (Winkelmann, 1971 ; pers. comm.). Griffiths (1978) makes a case for a liquid hydrostat model in these microchiropteran bats where intrinsic tongue muscles surround enlarged lingual veins that are in the wall of the tongue. Muscles radially compress blood in the veins as well as the tongue itself. Blood is forced an- 
teriorly to lengthen and stiffen the tongue. Veins occupy $40 \%$ of cross-sectional area at the tip of the tongue. However, under either model rapid movement and weight of the tongue well beyond the anterior end of the skull of a flying mammal must require a certain amount of structural integrity at the anterior end of the mandible, particularly with a concurrent reduction in jaw musculature in microchiropteran nectarivores. Fusion at the mandibular symphysis and bracing at the canines would provide such support.

\section{CONCLUSIONS}

Microchiropteran and megachiropteran nectarivores share many characteristics that differ from microchiropteran frugivores and animalivores but not from megachiropteran frugivores. These features including long, narrow palates; greater lengths from the fulcrum of the jaw joint to the last lower molar; thinner dentaries; narrower dentary condyles; smaller total tooth areas; smaller molariform areas; presence of space between the cheekteeth; and less distinct glenoid fossae. However, both micro- and megachiropteran nectarivores have diminutive cheekteeth and relatively large canines.

Microchiropteran nectarivores not only have long, narrow palates; they also have long, narrow heads. Megachiropterans in contrast, have substantially wider zygomata and greater jaw musculature, indicating more generalized diets. Glenoid fossae of the most derived microchiropteran nectarivores appear to restrict movement of dentary condyles laterally and have small postglenoid processes.

Megachiropteran frugivores differ from megachiropteran nectarivores by having distinctly larger total tooth areas, especially anterior premolars. Microchiropteran frugivores also have large premolars, which may indicate that frugivory requires larger teeth more anterior to the jaw. Animalivorous bats not only have a greater contribution of teeth at the back of the jaw, but teeth occupy a greater percentage of the entire palate.

Nectarivory, frugivory and carnivory probably all evolved independently from an insectivorous microchiropteran ancestor. In contrast, because there are many similarities between megachiropteran frugivory and nectarivory, these bats probably evolved from each other and not independently from some insectivorous ancestor.

Finally, nectarivory requires a jaw structure that can support the weight of the tongue beyond the anterior margin of the jaws. This support includes fusion as the mandibular symphysis, and a system where the lower canines are braced against the upper canines while the tongue works beyond the end of the jaws.

\section{ACKNOWLEDGEMENTS}

I am grateful to curators and staff at the American Museum of Natural History; United States National Museum, Fish and Wildlife Labs; and Texas Tech University for new specimens used in this study. Previous specimens from Royal Ontario Museum; University of Kansas, Museum of Natural History; University of California, Berkeley, Museum of Vertebrate Zoology; University of Michigan, Museum of Zoology; and 
Texas A \& M University, Texas Cooperative Wildlife Collection were also used. W. Standley at Field Museum and T. Holmes and R. Timm at the University of Kansas were also particularly helpful. Pauline Denham, technical artist for the Museum, skillfully constructed graphics from STATVIEW as well as illustrated the subtleties of glenoid fossae. I am grateful. Special thanks go to C. Lemen for helping me manipulate data sets from earlier work, for guiding me through different software programs, and for unending support and encouragement.

\section{REFERENCES}

Beecher RM. 1979. Functional significance of the mandibular symphysis. Journal of Morphology, 159: $117-130$

Brooke AP. 1994. Diet of the fishing bat, Noctilio leporinus (Chiroptera: Noctilionidae). Journal of Mammalogy 75: 212-218.

Every RG. 1965. The teeth as weapons, their influence on behavior. Lancet 1: 685-688.

Every RG. 1970. Sharpness of teeth in man and other primates. Postilla 143: 1-30.

Freeman PW. 1979. Specialized insectivory: Beetle-eating and moth-eating molossid bats. Journal of Mammalogy 60: 467-479.

Freeman PW. 1981. Correspondence of food habits and morphology in insectivorous bats. Journal of Mammalogy 62: 166-173.

Freeman PW. 1984. Functional cranial analysis of large animalivorous bats (Microchiroptera). Biological Journal of the Linnean Society 21: 387-408.

Freeman PW. 1988. Frugivorous and animalivorous bats (Microchiroptera): dental and cranial adaptations. Biological Journal of the Linnean Society 33: 249-272.

Freeman PW. 1992. Canine teeth of bats (Microchiroptera): size, shape, and role in crack propagation. Biological Journal of the Linnean Society 45: 97-115.

Gardner AL. 1977. Feeding habits. In: Baker RJ, Jones JK Jr, Carter DC, eds. Biology of bats of the New World family Phyllostomatidae. Part II. Special Publications, The Museum, Texas Tech University 13: 193-250.

Greaves WS. 1980. The mammalian jaw mechanism-the high glenoid cavity. American Naturalist 116: 432-440. Greaves WS. 1985. The generalized carnivore jaw. Zoological Journal of the Linnean Society 85: 267-274.

Griffiths TA. 1978. Muscular and vascular adaptations for nectar-feeding in the glossophagine bats Monophyllus and Glossophaga. Journal of Mammalogy 59: 414-418.

Griffiths TA. 1982. Systematics of the New World nectar-feeding bats (Mammalia, Phyllostomidae), based on the morphology of the hyoid and lingual regions. American Museum Novitates 2742: 1-45.

Griffiths TA. 1985. Molar cusp patterns in the bat genus Brachyphylla: some functional and systematic observations. Journal of Mammalogy 66: 544-549.

Hildebrand M. 1988. Analysis of Vertebrate Structure. Third Edition. New York: John Wiley \& Sons, Inc.

Hill JE. 1963. Revision of the genus Hipposideros. Bulletin of the British Museum, Zoology 11: 129.

Hill JE, Smith JD. 1984. Bats: a natural history. Austin: University of Texas Press.

Howell DJ. 1974. Bats and pollen: physiological aspects of the syndrome of chiropterophily. Comparative Biochemistry and Physiology 48A: 263-276. 
Kier WM, Smith KK. 1985. Tongue, tentacles and trunks: the biomechanics of movement in muscular- hydrostats. Zoological Journal of the Linnean Society 83: 307-324.

Koopman KF, MacIntyre GT. 1980. Phylogenetic analysis of chiropteran dentition. In: Wilson DE, Gardner AL, eds. Proceedings of the International Bat Research Conference. Lubbock: Texas Tech Press, 279-288.

Kruuk H, Sands WA. 1972. The aardwolf (Proteles critatus Sparrman) 1783 as predator of termites. East African Wildlife Journal 10: 211-227.

Marshall AG. 1983. Bats, flowers and fruit: evolutionary relationships in the Old World. Biological Journal of the Linnean Society 20: 115-135.

Marshall AG. 1985. Old World phytophagous bats (Megachiroptera) and their food plants: a survey. Zoological Journal of the Linnean Society 83: 351-369.

Miller GS, Jr. 1907. The families and genera of bats. United States National Museum Bulletin 57: xvi $+1-282$.

Phillips CJ. 1971. The dentition of glossophagine bats: Development, morphological characteristics, variation, pathology, and evolution. University of Kansas Museum of Natural History, Miscellaneous Publications 54: 1-138.

Scapino RP. 1965. The third joint of the canine jaw. Journal of Morphology 116: 23-50.

Slaughter BH. 1970. Evolutionary trends of chiropteran dentitions. In: Slaughter BH, Walton DW, eds. About Bats. Dallas, Texas: Southern Methodist University Press, 51-83.

Silva Taboada G, Pine RH. 1969. Morphological and behavioral evidence for the relationship between the bat genus Brachyphylla and the Phyllonyncterinae. Biotropica 1: 10-19.

Smith KK, Kier WM. 1989. Trunks, tongues, and tentacles: Animal movement with muscular skeletons. American Scientist 77: 28-35.

Smith KK, Redford KH. 1990. The anatomy and function of the feeding apparatus in two armadillos (Dasypoda): anatomy is not destiny. Journal of Zoology 222: 27-47.

Storch G. 1968. Funktionsmorphologische Untersuchungen an der Kaumuskulatur und an korrelierten Schadelstrukturen der Chiropteren. Abhandlungen der senckenbergischen naturforschenden Gesellschaft 517: 1-92.

Winkelmann JR. 1971. Adaptations for nectar-feeding in glossophagine bats. Unpublished D.Phi1. Thesis, University of Michigan, Ann Arbor.

Vaughan TA. 1986. Mammalogy. Third Edition. Philadelphia: W. B. Saunders Company. 


\section{APPENDIX 1.}

\author{
Phyllostomid nectarivores (nectar) \\ 3. Phyllonycteris poeyi \\ 4. Erophylla sezekorni \\ 5. Glossophaga soricina \\ 6. Glossophaga longirostris \\ 7. Monophyllus plethodon \\ 8. Monophyllus redmani \\ 9. Lichonycteris obscura \\ 10. Leptonycteris curasoae \\ 11. Anoura caudifer \\ 12. Anoura geoffroyi \\ 13. Hylonycteris underwoodi \\ 14. Choeroniscus godmani \\ 15. Choeroniscus intermedius \\ 16. Choeronycteris mexicana \\ 17. Musonycteris harrisoni \\ 18. Lonchophylla thomasi \\ 19. Lonchophylla handleyi \\ 20. Lionycteris spurrelli
}

Nectarivorous megachiropterans

(MEGAn):

Macroglossinae:

21. Eonycteris spelaea

22. Eonycteris major

23. Megaloglossus woermanni

24. Macroglossus minimus

25. Macroglossus sobrinus

26. Syconycteris australis

27. Melonycteris melanops

28. Notopteris macdonaldi other:

29. Pteropus scapulatus

33. Epomops buettikoferi

34. Scotonycteris zenkeri

Frugivorous megachiropterans

\section{(MEGAf)}

30. Acerodon jubatus

31. Dobsonia moluccensis

32. Harpyionycteris whiteheadi

35. Nyctimene draconilla

36. Nyctimene major

Frugivores (fruit) :

1. Brachyphylla nana

2. Brachyphylla cavernarum
37. Artibeus jamaicensis

38. Artibeus phaeotis

39. Artibeus toltecus

40. Carollia perspicillata

41. Sturnira lilium

42. Ametrida centurio

43. Artibeus lituratus

44. Centurio senex

45. Ectophylla alba

46. Pygoderma bilabiatum

47. Sphaeronycteris toxophyllum

Animalivores (animal) :

48. Saccolaimus peli

49. Taphozus nudiventris

50. Noctilio leporinus

51. Nycteris grandis

52. Macroderma gigas*

53. Megaderma lyra

54. Cardioderma cor

55. Rhinolophus luctus

56. Rhinolophus rufus

57. Hipposideros commersoni gigas *

58. Hipposideros commersoni commersoni

59. Hipposideros lankadiva

60. Hipposideros pratti

61. Vampyrum spectrum

62. Phyllostomus hastatus

63. Chrotopterus auritus

64. Trachops cirrhosus

65. Scotophilus nigrita gigas*

66. Ia io

67. Myotis myotis

68. Nyctalus lasiopterus*

69. Cheiromeles torquatus

70. Eumops perotis

71. Eumops underwoodi*

72. Otomops martiensseni*

73. Peropteryx kappleri*

74. Rhinolophus blasii*

75. Hipposideros ruber*

76. Macrotus californicus*

77. Lasiurus borealis*

78. Myotis velifer*

79. Tadarida brasiliensis *

80. Molossus molossus *

*Species not included in certain areal quantities. 


\section{APPENDIX 2}

\section{Measurements}

1. Condylocanine length (CCL)

2. Maxillary toothrow (MTR) - also length of palate.

3. Zygomatic breadth

4. Width across canines

5. Greatest width across the molars - also breadth of palate

6. Height of upper canine - called length in Freeman, 1988.

7. Depth of temporalis

8. Length of temporalis

9. Height of temporalis

10. Origin of masseter - particularly difficult in phyllostomid nectarivores

11. Depth of masseter

12. Height of lower canine

13. Length of dentary

14. Length from condyle to $\mathrm{M}_{1}$ - to anterior edge of $\mathrm{M}_{1}$ in megachiropterans

15. Length from condyle to $\mathrm{M}_{3}$ or $\mathrm{M}_{2}$ - from midpoint of dentary condyle to posteriormost edge of most posterior tooth in toothrow (this true also for previous work but described only as $\mathrm{M}_{3}$; Freeman, 1988)

16. Moment arm of temporalis

17. Moment arm of masseter - from dorsal midpoint of dentary condyle to midpoint of masseter insertion on ventral border of angular process (true also for Freeman, 1988)

18. Height of the coronoid

19. Thickness of dentary

20. Mediolateral depth of dentary

21. Mediolateral width of condyle - greatest distance across the long axis of the dentary condyle (called condyle length in Freeman, 1988).

22. Length of upper molariform row - includes $\mathrm{P}^{4}$ and all upper molars.

23. Height of condyle - height of dentary condyle with relationship to the lower toothrow. For microchiropterans taken in lateral view from a line (cross hair in scope) through the valleys between protoconids and hypoconids of molars to the dorsal edge of condyle. In megachiropterans line is aligned just below cingula of $\mathrm{PM}^{3}, \mathrm{PM}^{4}$, and $\mathrm{M}^{2}$ to dorsal edge of condyle. The condyle is below this line in many megachiropterans and produces a negative value.

24. Area of palate (PAL)* - In megachiropterans the posterior boundary was taken at the corners of palatal emargination, not at anteriormost margins, to incorporate the corners of the natural hard palate. Taken with digitizer from drawing as are all areas.

25. Total tooth area (TTA)* - occlusal area of all teeth on the palate.

26. Area of canines (Canine)* - occlusal area of both canines.

27. Area of incisors (Incisor)* - occlusal area of incisors. Procumbent incisors occupy more area than non-procumbent ones.

28. Area of non-molariform premolars (Other PMs)* - occlusal area of premolars anterior to $\mathrm{PM}^{4}$ on both sides of the palate.

29. Area of molariform row $\left(\mathrm{PM}^{4}+\mathrm{Ms}\right)$ - occlusal area of molars and $\mathrm{PM}^{4} \mathrm{~s}$ on both sides of the palate.

30. Area of stylar shelf of molariform teeth (Shelf) - occlusal area of stylar shelf (or ectoloph) of molars and $\mathrm{PM}^{4} \mathrm{~s}$ on both sides of the palate.

31. Area of $\mathrm{M}^{3}\left(\mathrm{M}^{3}\right)$ - occlusal area of both $\mathrm{M}^{3} \mathrm{~s}$.

32. SIZE - the sum of the natural logs of condylocanine length, zygomatic breadth, and temporal height.

** Described earlier (Freeman, 1988) except where noted.

* Quantities missing for species noted in Appendix 1. 